This is a self-archived version of an original article. This version may differ from the original in pagination and typographic details.

Author(s): Juhola, Riikka; Runtti, Hanna; Kangas, Teija; Hu, Tao; Romar, Henrik; Tuomikoski,

Title: Bisphenol A removal from water by biomass-based carbon : Isotherms, kinetics and thermodynamics studies

Year: 2020

Version: Accepted version (Final draft)

Copyright: (c) 2018 Taylor \& Francis

Rights: In Copyright

Rights url: http://rightsstatements.org/page//nC/1.0/?language=en

Please cite the original version:

Juhola, R., Runtti, H., Kangas, T., Hu, T., Romar, H., \& Tuomikoski, S. (2020). Bisphenol A removal from water by biomass-based carbon : Isotherms, kinetics and thermodynamics studies.

Environmental Technology, 41(8), 971-980. https://doi.org/10.1080/09593330.2018.1515990 


\section{Bisphenol A removal from water by biomass-based carbon: Isotherms, kinetics and thermodynamics studies}

Riikka Juhola, Hanna Runtti, Teija Kangas, Tao Hu, Henrik Romar \& Sari Tuomikoski

To cite this article: Riikka Juhola, Hanna Runtti, Teija Kangas, Tao Hu, Henrik Romar \& Sari Tuomikoski (2018): Bisphenol A removal from water by biomass-based carbon: Isotherms, kinetics and thermodynamics studies, Environmental Technology, DOI: 10.1080/09593330.2018.1515990

To link to this article: https://doi.org/10.1080/09593330.2018.1515990

Accepted author version posted online: 23

Aug 2018.

Submit your article to this journal

View Crossmark data $₫$ 
Publisher: Taylor \& Francis \& Informa UK Limited, trading as Taylor \& Francis Group

Journal: Environmental Technology

DOI: $10.1080 / 09593330.2018 .1515990$

\section{Bisphenol A removal from water by biomass-based carbon:}

\section{Isotherms, kinetics and thermodynamics studies}

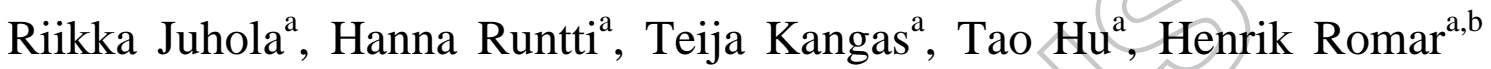
and Sari Tuomikoski ${ }^{{ }^{*}}$

${ }^{a}$ University of Oulu, Research Unit of Sustainable Chemistry, P.O. Box 4300, FI-90014 University of Oulu, Finland.

${ }^{b}$ University of Jyvaskyla, Kokkola University Consortium Chydenius, Unit of Applied Chemistry, Talonpojankatu 2B, FI-67100 Kokkola, Finland.

*Corresponding author: E-mail: sari.tuomikoski@oulu.fi; tel. +358 294481644 


\section{Bisphenol A removal from water by biomass-based carbon:}

\section{Isotherms, kinetics and thermodymamics studies}

Biomass-based carbon was modified and used as an efficient bisphenol A (BPA) sorbent. The simple and environmentally friendly modification method produced sorbent with a capacity of $\mathbf{4 1 . 5} \mathbf{~ m g} / \mathbf{g}$. The raw material was modified with $\mathbf{F e C l}_{3}$ (Fe-CR), treated with hydrochloric acid (H-CR) or modified with $\mathrm{CaCl}_{2}(\mathrm{Ca}-$ CR). Batch sorption experiments were performed to evaluate the effects of the initial $\mathrm{pH}$, sorbent dosage, temperature, and contact time on BPA removal. BPA removal with modified carbons was notably higher than that with unmodified carbon. All sorbent materials exhibited very high sorption capacities and compared favourably to materials reported in the literature. Several isotherms were applied to describe the experimental results of Fe-CR, H-CR, and Ca-CR modified carbon residues and the Sips model showed the best fit for all sorbents. Kinetic studies for the best sorbent material (Fe-CR) showed that the sorption process follows Elovich kinetics. Desorption cycles were implemented, and sorption capacity remained with three cycles.

Keywords: biomass-based carbon; activated carbon; environmentally friendly; sorption; bisphenol A

\section{Introduction}

Bisphenol A (BPA) is an anthropogenic compound, initially synthesised in 1890 and used commercially since the 1950s [1]. BPA is an endocrine-disrupting chemical (EDC), which can cause abnormalities in the endocrine system functions of humans and other living organisms. Even minor doses of this emerging pollutant can create permanent character changes in mature living beings [2, 3]. Nevertheless, BPA monomers are used in the production of epoxy resins, polycarbonate plastics, and flame retardants. Researchers have found that BPA leaches from the abovementioned products under normal use conditions [2-5]. The major source of BPA release in the environment is industrial wastewater, such as landfill leachate and water used to wash BPA products, that is ultimately treated in wastewater treatment plants (WWTPs) [6]. BPA is listed as 
an emerging pollutant. Complete removal of EDCs cannot be achieved in biological processes; More than 120 WWTPs worldwide have been studied for BPA levels and removal capacity $[5,7,8]$. Information about the harmfulness of BPA is contradictory. The European Commission stated in 2008 that BPA causes no danger for humans, and in 2010, the European Food Safety Authority agreed that current BPA usage in food packaging is not a risk to humans [9]. By contrast, the government of Canada concluded that BPA may enter the environment in amounts sufficient to cause a danger to human health [10]. In 2010, the US Environmental Protection Agency concluded that BPA may cause a potential risk to aquatic organisms at the current concentration levels [9]. Canada, USA, and the EU are aligned that BPA use in baby bottles is forbidden due to risk assessment $[9,10]$. In addition, the European Commission is currently preparing regulations concerning the use of BPA in varnishes and coatings intended to come into contact with food. This indicates that the Commission may have softened their 2008 stance that BPA causes no danger to humans in any circumstances.

The treatment of BPA-containing water is problematic because of the lack of appropriate methods. Continuous long-lasting industrial usage of BPA and other EDCs have resulted in these chemicals being detected in wastewater, surface water, sediments, groundwater and drinking water [11-15], since the conventional water treatment in WWTPS is ineffective in the removal of these chemicals $[4,16,17]$. BPA concentration has been found to be $17.2 \mathrm{mg} / \mathrm{L}$ in landfill leachates [18], $12 \mu \mathrm{g} / \mathrm{L}$ in stream water [19], and $0.42 \mu \mathrm{g} / \mathrm{L}$ in drinking water [20]. Concentrations at the level of $0.23 \mathrm{pg} / \mathrm{L}$ or higher have estrogenic activity [21]. Several technologies have been studied to achieve high BPA removal, such as ozonation, ultrasonication and advanced oxidation [22]. However, there is an open question of costs, effectiveness, and suitability at a larger scale. 
The harmfulness of BPA and the challenges in wastewater treatment render research into removal technologies for BPA vital. From the technical and economical points of view, sorption is promising alternative for the removal of unfavourable compounds in wastewater. However, the disposal of many kinds of industrial byproducts is expensive and does not fulfil the criteria of sustainability in the industrial field. These two problems are addressed in combination in those studies where the usage possibilities of byproducts as sorbents are examined. Several commercially available activated carbons have been studied in the removal of BPA from aqueous solution [4, 23-25]. Byproducts from different industries and biomass-based materials have also been used as precursors for carbonaceous sorbent production [23, 24, 26, 27]. The main disadvantages of the methods are the usage of hazardous and expensive chemicals, high temperatures and multi-step production processes.

The aims of this research was to study the removal of BPA from the model solution using modified biomass-based carbon formed in a wood gasification processes as a sorbent. The studied process was considered from the ecological and economic standpoints. Sorbent material was chosen for ready availability and modification was done at room temperature in ambient pressure using non-hazardous and inexpensive chemicals. Sorption conditions ( $\mathrm{pH}$, sorbent dosage, and reaction time) were optimized, and several desorption cycles of BPA from the sorbent surface were studied to ensure the possibility of reusing of sorbent. Sorption experiments were performed in three different temperatures to solve the thermodynamic parameters of the system. Results were analysed via several kinetic and sorption isotherm models to experimental results. Intermediates formed during sorption-desorption processes were analysed to clarify the sorption mechanism and to evaluate the possible organic degradation products. 


\section{Experiments and methods}

\subsection{Materials}

Biomass-based carbon residue (CR) obtained from a biomass gasification pilot plant (Sievi, Finland) served as the raw material for the sorbent preparation. A downdraft gasifier $(150 \mathrm{~kW})$ operating at $1000^{\circ} \mathrm{C}$ was employed, and wood chips (pine and spruce) were used as the raw materials for fuel, at a feeding rate of $50 \mathrm{~kg} / \mathrm{h}$. To ensure uniformity and product quality, all materials were dried overnight at $110^{\circ} \mathrm{C}$, crushed, and sieved to obtain a particle size less than $150 \mu \mathrm{m}$ before use.

\subsection{Acid washing}

To reduce the ash content by selectively removing mineral components, $\mathrm{CR}$ was washed with a $1 \mathrm{~N}$ solution of $\mathrm{HCl}$ and $\mathrm{H}_{2} \mathrm{SO}_{4}$ (1:1) for 24-29 h at a liquid-to-solid (L/S) ratio of $10(\mathrm{w} / \mathrm{w})$. The CR samples were filtered and washed with distilled water using an L/S ratio of $40(\mathrm{w} / \mathrm{w})$ for at least $1 \mathrm{~h}$. The samples were then filtered and dried at $110{ }^{\circ} \mathrm{C}$ overnight before being crushed and sieved to achieve particles of uniform quality (< $150 \mu \mathrm{m})$.

\subsection{Chemical modification}

Protocol 1, $1 \mathrm{M} \mathrm{CaCl}_{2}$ : Carbon residue was mixed with $1 \mathrm{M}$ calcium chloride, $\mathrm{CaCl}_{2}$ (Ca-CR), with an $\mathrm{L} / \mathrm{S}$ ratio of $10(\mathrm{w} / \mathrm{w})$. The mixture was shaken with a magnetic stirrer at room temperature for $18 \mathrm{~h}$, filtered, washed carefully with distilled water, dried at $110^{\circ} \mathrm{C}$ overnight, crushed, and sieved.

Protocol 2, $\mathrm{HCl}$ : Carbon residue was mixed with $1 \mathrm{M}$ hydrochloric acid, $\mathrm{HCl}$ (H-CR), with an $\mathrm{L} / \mathrm{S}$ ratio of $10(\mathrm{w} / \mathrm{w})$. The mixture was shaken with a magnetic stirrer at room temperature for $18 \mathrm{~h}$, filtered, washed carefully with distilled water, dried at $110^{\circ} \mathrm{C}$ overnight, crushed, and sieved.

Protocol 3, 5.0\% $\mathrm{FeCl}_{3}(\mathrm{w} / \mathrm{w})$ : Carbon residue was mixed with 5.0\% iron (III) chloride (w/w), $\mathrm{FeCl}_{3}(\mathrm{Fe}-\mathrm{CR})$ solution and the $\mathrm{pH}$ of the mixture was adjusted between 4-5 with $4 \mathrm{M} \mathrm{NaOH}$ solution to enable the formation of iron precipitate. The mixture was shaken with magnetic stirrer for $16 \mathrm{~h}$ at room temperature, filtered, washed with distilled water, dried at $110^{\circ} \mathrm{C}$ overnight, crushed, and sieved [28]. 


\subsection{Characterization methods}

The pore size, pore volume, and specific surface area of the sorbents were determined from nitrogen sorption-desorption isotherms at the temperature of liquid nitrogen (-196 ${ }^{\circ} \mathrm{C}$ ), using a Micromeritics ASAP 2020 (Norcross, GA, USA). Prior to measurements the samples were degassed for 180 minutes at $2 \mu \mathrm{m} \mathrm{Hg}$ and $140{ }^{\circ} \mathrm{C}$. BPA concentration was analysed in the filtrate solution by a Shimadzu UV-1800 Spectrophotometer or by an HPLC (High Performance Liquid Chromatography) equipped with an ultravioletvisible (UV-VIS) detector, using a $226 \mathrm{~nm}$ wavelength (Shimadzu SPD-10A), acetonitrile $45 \%$ and formic acid $0.1 \%$ as an eluent, a flow rate of $0.5 \mathrm{~mL} / \mathrm{min}$, and an operating temperature of $30^{\circ} \mathrm{C}$. Compounds were separated by a SunFireTM C18 $5 \mathrm{~m} 2$ L x 100 mm column.

ICP-OES (Perkin Elmer Optima 5300 DV) was used to measure the iron content of the sorbent; the possible leached iron after sorption experiments was detected by AAS (Atomic Absorption Spectrometer, Perkin Elmer AAnalyst 200) from the liquid phase at a wavelength of $248.3 \mathrm{~nm}$. FESEM (Field emission scanning electron microscopy, Zeiss ULTRA plus) equipped with EDS (Energy-Dispersive X-ray Spectroscopy) was used to study the morphology and elemental composition of the FeCR sorbent.

Liquid chromatography time-of-flight mass spectrometry (LC-TOF-MS, Waters AcQuity $^{\mathrm{TM}}$ UPLC system paired with Waters Synapt G1) operated in negative ionisation mode was used for the identification of possible BPA intermediates after desorption experiments. LC analyses were run with water and acetonitrile as the mobile phase, with a flow rate of $0.4 \mathrm{~mL} / \mathrm{min}$. The compounds were separated using an AcQuity UPLC®BEH C18 1.7 um, 2.1 x $100 \mathrm{~mm}$ column at an operating temperature of $30^{\circ} \mathrm{C}$. The total chromatographic run time was $6 \mathrm{~min}$.

\subsection{Batch sorption experiments}

The effects of initial $\mathrm{pH}$, sorbent dosage, and contact time on the removal of BPA were studied in each sorbent. To determine the optimum initial $\mathrm{pH}$ for BPA sorption by different sorbent materials, batch equilibrium studies were carried out at $\mathrm{pH}$ values of 2-8 using an initial concentration of $60 \mathrm{mg} / \mathrm{L}$ BPA solution, which was prepared by diluting solid BPA in MilliQ water. The $\mathrm{pH}$ of the solution was adjusted with $\mathrm{HCl}$ and/or $\mathrm{NaOH}$. CR is a strongly alkaline material with a high buffering capacity [29], so $\mathrm{pH}$ adjustment was performed after adding the sorbent to the BPA solution to ensure the 
correct $\mathrm{pH}$ during the experiment. The bottles were placed on a laboratory shaker using a reciprocating motion at room temperature for $24 \mathrm{~h}$. The $\mathrm{pH}$ optimisation experiments were performed using polyethylene flasks, and the sorbent dosage was $5.0 \mathrm{~g} / \mathrm{L}$. Sorbent dosage optimisation tests were done with a sorbent mass of $1.0-25 \mathrm{~g} / \mathrm{L}$. When the $\mathrm{pH}$ and sorbent dosage optimisation experiments were completed, the effect of contact time was studied in the optimised conditions in a $2 \mathrm{~L}$ reactor vessel equipped with a magnetic stirrer at $1000 \mathrm{rpm}$, using an optimum $\mathrm{pH}$, sorbent dosage of $5.0 \mathrm{~g} / \mathrm{L}$, and initial BPA concentration of $60 \mathrm{mg} / \mathrm{L}$. Samples were collected regularly between 1 and 1440 minutes. All sorption experiments were performed at room temperature, and all $\mathrm{pH}$ and concentration optimisation experiments were duplicated. All samples, including the initial samples, were centrifuged before filtering.

The reusability and regeneration of the sorbents were tested by running three sorption-desorption cycles using ethanol as a removing agent. The experiments were performed at the optimised conditions at room temperature using a $0.5 \mathrm{~L}$ reactor vessel equipped with a magnetic stirrer at $1000 \mathrm{rpm}$. The initial concentration of BPA solution was $60 \mathrm{mg} / \mathrm{L}$. During the sorption cycle (24h) one sample was collected after $24 \mathrm{~h}$ constant time. Samples taken during the desorption were collected between 1 and 1440 minutes. All samples were filtrated prior to BPA concentration measurements by HPLC.

\subsection{Sorption isotherms}

Sorption isotherms are models based on the experimental data that describe the sorption capacity at variable sorbent masses. Langmuir [30], Freundlich [31], Dubinin-Raduschkevich (DR) [32], Temkin [33], Redlich-Peterson (RP) [34], Toth [35] and Sips [36] models, introduced in Table 1 (supplementary data), were applied to the experimental mass optimisation data. Isotherm parameters were obtained using nonlinear regression with the OriginPro 2017. Calculated sorption capacities at the equilibrium $\mathrm{q}_{\mathrm{e}(\mathrm{calc})}(\mathrm{mg} / \mathrm{g})$ were compared to the experimental ones which were calculated from the equation:

$$
q_{e(\exp )=\frac{\left(C_{0}-C_{e}\right) V}{m_{a d s}},}
$$

where $m_{a d s}(\mathrm{~g})$ is the mass of the sorbent, $\mathrm{V}(\mathrm{L})$ is the volume of the solution, and $C_{0}$ and $C_{e}$ are the initial and equilibrium concentrations $(\mathrm{mg} / \mathrm{L})$ of BPA, respectively. 
Residual root mean square error (RMSE) and correlation coeffient value $\left(\mathrm{R}^{2}\right)$ were used to evaluate the functionality of the isotherm equations compared to the experimental data. The calculated expressions of error functions can be defined as follows:

$$
\begin{aligned}
& \text { RMSE }=\sqrt{\frac{1}{n-p} \sum_{i=1}^{n}\left(q_{e(\exp )}-q_{e(\text { calc })}\right)^{2}}, \\
& R^{2}=1-\frac{\sum_{n=1}^{n}\left(q_{e, \text { exp }, n}-q_{e, \text { model }, n}\right)^{2}}{\sum_{n=1}^{n}\left(q_{e, \text { exp }, n}-\overline{q_{e, \text { exp }, n}}\right)^{2}}
\end{aligned}
$$

where $n$ is the number of experimental data points, $p$ is the number of parameters and $q_{\text {e(ехр) }}$ and $q_{\text {e(calc) }}$ are the experimental and calculated values, respectively, of sorption capacity in equilibrium [37, 38]. A small error function value indicates a good fit.

\subsection{Kinetic modelling}

The pseudo-first-order [39], pseudo-second-order [40] and Elovich [41] kinetic models were used to describe the sorption kinetics. Kinetic parameters were obtained using nonlinear regression with the OriginPro 2017. Table 2 (supplementary data) presents the non-linear equations of these models.

The diffusion mechanism was analysed using the intraparticle diffusion model introduced by Weber and Morris [42]:

$$
q_{t}=k_{i d} t^{1 / 2}+\mathrm{C}
$$

where $k_{\text {id }}\left(\mathrm{mg} \mathrm{g}^{-1} \mathrm{~min}^{-1 / 2}\right.$ ) is the intraparticle diffusion on the rate determining step and $\mathrm{C}$ is the intercept related to the thickness of the boundary layer. Residual root mean square error (RMSE, equation 2) and correlation coeffient value $\left(\mathrm{R}^{2}\right.$, equation 3 ) were also used to evaluate the functionality of the kinetic model compared to the experimental data.

\subsection{Sorption thermodynamics}

Van’t Hoff equation's form 


$$
\ln K=\frac{\Delta S}{R}-\frac{\Delta H}{R T}
$$

was used to solve the change in enthalpy $(\Delta H)$ and entropy $(\Delta S)$ during the sorption process by drawing the $\ln \mathrm{K}$ versus $1 / \mathrm{T}$ and solving $\Delta H$ from the slope and $\Delta S$ from the intercept of the equation of the linear diagram. In equation $5, R$ is the universal gas constant $(8.314 \mathrm{~J} / \mathrm{mol} \mathrm{K}), T$ is the temperature used in the experiments $(\mathrm{K})$, and $K(\mathrm{~L} / \mathrm{g})$ is the equilibrium constant calculated from the experimental results in equilibrium conditions by equation

$$
K=\frac{q_{e}}{C_{e}}
$$

The change in free energy $(\Delta G)$ in BPA sorption can be calculated using the equation

$$
\Delta G=-R T \ln K
$$

\section{Results and discussion}

\subsection{Sorbent characterisation}

Table 1 presents the specific surface areas, pore volume, and pore size for the studied materials before and after the sorption experiments at room temperature. Decrease in both specific surface area and total pore volume during sorption experiments can be observed, indicating BPA sorption to the surface. Pore size increases, which is probably due to the leaching of iron or calcium bound to the surface of the material. The specific surface area, pore size distribution, and pore volume are higher for the Fe-CR sorbent compared to the H-CR and Ca-CR sorbents. Fe-CR sorbent has a high mesoporosity and some macroporosity, whereas the other two sorbents are mostly micro- and mesoporous. Most sorption is known to occur in the micropores [43]. However, meso- and macropores are important as they function as a passageway for activating chemicals. Iron chloride has been generally used as an activating agent when preparing active carbon, and it has been reported to increase the surface area [44]. Therefore, the role of iron in surface formation and the different preparation methods used between the sorbents might explain the higher surface area and different porosity distribution of the Fe-CR sorbent.

Table 1 near here. 
The iron content of the Fe-CR sorbent analysed with ICP-OES, was 4.4 wt-\%, and it was found to be in good agreement with the target iron content (5 wt-\%). The EDS analysis confirmed this result, indicating the presence of iron with average value of 5.8 wt-\%, which was calculated using 20 small areas, analysing results obtained by EDS. The images obtained from FESEM (Figure 1) show heterogeneously dispersed iron particles $(<<1 \mu \mathrm{m})$ and a porous structure.

Figure 1 near here

\subsection{Effect of initial pH}

BPA sorption onto Fe-CR, H-CR, and Ca-CR was studied at $\mathrm{pH} \mathrm{2-8} \mathrm{(Figure} \mathrm{2).} \mathrm{The}$ highest sorption capacity and BPA removal is reached at $\mathrm{pH} 4$ for $\mathrm{Fe}-\mathrm{CR}$ and $\mathrm{Ca}-\mathrm{CR}$ and $\mathrm{pH} 5$ for H-CR. BPA occurs in electrically neutra/ species at these $\mathrm{pH}$ conditions, so no repulsive forces interfere with the sorption process. As the $\mathrm{pH}$ becomes more basic, BPA ionizes, and the repulsive forces between the sorbent surface and anion (bisphenolate) become significant, affecting the sorption process negatively. Figure 2 clearly shows this phenomenon for the Ca-CR sorbent; as the $\mathrm{pH}$ changes from 4 to 8 , BPA removal decreases from $85 \%$ to $55 \%$. By contrast, Fe-CR and H-CR can be seen to have wider working $\mathrm{pH}$ range. Fe-CR was found to have the highest BPA removal and sorption capacity ( $94 \%$ and $11.2 \mathrm{mg} / \mathrm{g}$, respectively).

Figure 2 near here.

\subsection{Effect of sorbent dosage and sorption isotherms}

The experiments to analyze the effect of sorbent dosage were done at the optimum $\mathrm{pH}$, and the studied dosages were 1.0-25 g/L. Figure 3 indicates that the removal of BPA increases rapidly as the sorbent dosage increases until 5-10 g/L, after which equilibrium is reached. The rapid removal is because more free sorption sites are available at the beginning [45]. At equilibrium, BPA removal remains almost unchanged, which may be the result of agglomeration of the sorbent $[45,46]$. By contrast, after exceeding the optimum dosage of sorbent, the viscosity of the solution may increase, reducing the free surface area due to agglomeration, and hence sorption is reduced [47]. Five g/L was 
selected as the optimum dosage for all sorbents because of high removal efficiency and sorption capacity.

Figure 3 near here.

Langmuir, Freundlich, DR, Temkin, RP, Toth, and Sips isotherms were applied to the experimental mass optimization data. According to the correlations coefficients and root mean square errors, the Sips isotherm was the most suitable model for all studied sorbents. Sips isotherms for all the sorbents are illustrated in Figure 4, and Table 2 presents isotherm parameters. Comparison for other sorption capacity of other materials have been presented in Table 3.

Table 2 and 3 and Figure 4 near here.

\subsection{Effect of contact time}

The effect of contact time was studied in optimum conditions at room temperature and 5 g/L sorbent: Initial $\mathrm{pH}$ was 4,5 , and 4 for Fe-CR, H-CR, and Ca-CR, respectively. Figure 5 illustrates the results. The sorption is very rapid and attains equilibrium almost immediately.

Figure 5 near here.

Pseudo-first-order, pseudo-second-order, and Elovich models were applied to the kinetic data. Table 4 presents the kinetic parameters. According to the correlation coefficients and root mean square errors, the Elovic model was the best fit for Fe-CR, the pseudo-second order model gave the best fit for Ca-CR, and both models had equal $\mathrm{R}^{2}$ values for $\mathrm{H}-\mathrm{CR}$. Figure 5 illustrates the best model for all three sorbents.

Table 4 near here. 


\subsection{Weber and Morris intraparticle diffusion model}

Kinetic data was also used to evaluate the mechanism of BPA sorption, applying the intraparticle diffusion model. Figure 6 presents the results; sorption is triphasic in all cases. In the first stage, the majority of BPA is sorbed when instantaneous sorption takes place on the external surface sites. In the next stage, the sorption capacity increases only slightly when BPA is sorbed onto the inner pores. In the third stage, the sorption rate stays almost constant because BPA concentration in the solution is low.

Figure 6 near here.

\subsection{Thermodynamic parameters}

Thermodynamic parameters of sorption processes were obtained from the slope and intercept of the Van't Hoff plot of $\ln K_{c}$ versus $1 / T$ and are listed in Table 5. The negative values of $\Delta G$ with all sorbents indicate that the sorption process is spontaneous. In addition, the positive values of $\Delta S$ reveal that entropy increases during the sorption process. The sorption is endothermic, since the $\Delta H$ is positive. However, the $\Delta H$ is smaller than $40 \mathrm{~kJ} / \mathrm{mol}$, which means that the process is based on physisorption involving weak interactions.

Comparison of the produced sorption materials shows that sorption of BPA on the surface of Fe-CR is the most spontaneous. In addition, the $\Delta H$ of the reaction is smaller for Fe-CR than with other materials. Figure 1 (supplementary data) shows the Van't Hoff plot for sorption of BPA removal by Fe-CR.

\section{Table 5 near here.}

\subsection{Desorption experiments}

The desorption experiments were carried out for the optimum sorbent material and identified Fe-CR; the results are shown in Figure 8. Approximately 40-50\% desorption efficiency was reached within $72 \mathrm{~h}$. While the sorption capacity can be observed to remain almost unchanged during the regeneration cycles of Fe-CR, the desorption capacity decreases slightly, from 5.6 to $4.9 \mathrm{mg} / \mathrm{g}$ (Table 6). These results indicate that 
Fe-CR is a stable material that can retain the pollutant; therefore, this material could be used in wastewater treatment processes.

Table 6 and Figure 7 near here.

\subsection{Degradation products and sorption mechanism}

There is also the possibility that BPA degrades during sorption because the solution may contain minor amounts of certain metals. The most promising material, $\mathrm{Fe}-\mathrm{CR}$, was modified with iron, which is a catalytically active metal [45, 46, 49]. Therefore, the possible degradation products were studied and detected by LC-MS and HPLC after BPA desorption from Fe-CR sorbent. The results showed that BPA (m/z $[\mathrm{M}-\mathrm{H}]^{-}$ 227.1045, MW: 228) and a possibly identified BPA dimer (m/z [M-H]- 453.2064, MW: 454) appeared with over $97 \%$ abundance [50, 51]. Other possible degradation products detected in trace amounts were A) $\mathrm{C}_{7} \mathrm{H}_{5} \mathrm{O}_{2}(\mathrm{~m} / \mathrm{z}[\mathrm{M}-\mathrm{H}]-121.0284$, MW: 122), B) $\mathrm{C}_{8} \mathrm{H}_{8} \mathrm{O}_{2}\left(\mathrm{~m} / \mathrm{z}[\mathrm{M}-\mathrm{H}]^{-}\right.$135.0434, MW: 136), C) $\mathrm{C}_{15} \mathrm{H}_{15} \mathrm{O}_{2}$ (m/z [M-H] 223.0265, MW:

$$
\text { D) } \mathrm{C}_{15} \mathrm{H}_{15} \mathrm{O}_{3}\left(\mathrm { m } / \mathrm { z } \quad [ \mathrm { M } - \mathrm { H } ] ^ { - } \text { 243.1009, MW: 244), E) } \mathrm { C } _ { 3 } \mathrm { H } _ { 2 9 } \mathrm { O } _ { 4 } \left(\mathrm{~m} / \mathrm{z}[\mathrm{M}-\mathrm{H}]^{-}\right.\right.
$$
453.2055, MW: 454), and F) $\mathrm{C}_{45} \mathrm{H}_{43} \mathrm{O}_{6}(\mathrm{~m} / \mathrm{z} \text { [M-H] }]^{-}$679.3056, MW: 680). Some of these compounds have elsewhere been identified as BPA oxidation intermediates/products, such as p-hydroxybenzaldehyde (compound A, [52]) and phydroxyacetophenone (compound B, [52-54]). For compounds D, E, and F, tentative structures have been reported by Potakis et al. (2017) [51] and Poerschmann et al. (2010) [50]. The possible leakage of iron ions from the Fe-CR sorbent was analyzed after the $24 \mathrm{~h}$ sorption experiment by AAS at $\mathrm{pH} 4$, and $0.1-0.3 \mathrm{mg} / \mathrm{L}$ leaching of iron was observed. The homogenous Fenton process is effective only when enough iron (50$80 \mathrm{mg} / \mathrm{L}$ ) exists, which was not the case during these experiments [55].

BPA is present mainly as an electrically neutral species at $\mathrm{pH}$ 4-9. It can deprotonate to monovalent anions at $\mathrm{pH} 7-12$, and it starts to form divalent anions at $\mathrm{pH}$ 9 [7, 52, 56, 57]. Some degradation products exist, as listed above. However, BPA remains mainly undegraded, which was ensured in sorption-desorption cycle experiments. It can be hypothesized that iron is in oxidized form on the sorbent surface and so could form molecular coordination with BPA [45, 46]. 


\section{Conclusions}

Carbon residue from the wood gasification process modified with iron, acid washing, or calcium were studied for BPA removal. Fe-modified carbon residue exhibited higher removal capacity than Ca-modified or acid-washed material. The higher surface area of Fe-modified samples explains this result. The optimum $\mathrm{pH}$ required for maximum sorption was found to be 4 for Ca-modified and Fe-modified carbons and 5 for acidwashed carbon. The maximum experimental sorption capacities were 41.5, 23.8, and $16.8 \mathrm{mg} / \mathrm{g}$ for Fe-modified, acid-washed, and Ca-modified carbon residue, respectively. The Sips isotherm model described the sorption well. Sorption kinetics followed the Elovic model, and the Weber and Morris intraparticle diffusion model showed that the sorption mechanism included three different steps. The positive enthalpy value indicates that the sorption process was endothermic. The results from the present study indicate that Fe-modified carbon residue could be a technically feasible BPA sorbent for wastewater treatment.

\section{Acknowledgments}

This study was undertaken with the financial support of the Maa-ja Vesitekniikan tuki Ry and Jätehuoltoyhdistys. The authors would like to thank Marine Guillotin and Florian Chevalier for their contribution in certain laboratory experiments. The authors would also like to thank Mrs. Seija Liikanen for her assistance in ICP-OES measurements and Mrs. Päivi Joensuu for her assistance in BPA concentration measurements.

\section{Refererences}

[1] Vogel SA. The politics of plastics: the making and unmaking of bisphenol a "safety". Am J Public Health. 2009;99(S3):S559-566.

[2] Stasinakis AS, Kordoutis CI, Tsiouma VC, Gatidou G, Thomaidis NS. Removal of selected endocrine disrupters in activated sludge systems: Effect of sludge retention time on their sorption and biodegradation. Bioresour Technol. 2010;101(7):2090-2095.

[3] Duong CN, Ra JS, Cho J, Kim SD, Choi HK, Park J-, Kim KW, Inam E, Kim SD. Estrogenic chemicals and estrogenicity in river waters of South Korea and seven Asian countries. Chemosphere. 2010;78(3):286-293.

[4] Liu G, Ma J, Li X, Qin Q. Adsorption of bisphenol A from aqueous solution onto activated carbons with different modification treatments. J Haz Mat. 2009;164(23):1275-1280. 
[5] Melcer H, Klecka G. Treatment of wastewaters containing bisphenol A: State of the science review. Water Environ Res. 2011;83(7):650-666.

[6] Proposed Risk Management Approach for Phenol, 4,4'-(1-methylethylidene) bis (Bisphenol A), Chemical Abstract Service Registry Number (CAS RN) 80-05-7 [Internet]. Canada; Government of Canada; 2008 [cited 2017 Dec 11]. Available from: https://www.ec.gc.ca/ese-ees/6FA54372-A09E-45CD-8A5F-

39EBDD55D13A/batch2_80-05-7_rm_en.pdf

[7] Dong Y, Wu D, Chen X, Lin Y. Adsorption of bisphenol A from water by surfactant-modified zeolite. J Colloid Interface Sci. 2010;348(2):585-590.

[8] Nie Y, Qiang Z, Zhang H, Ben W. Fate and seasonal variation of endocrinedisrupting chemicals in a sewage treatment plant with A/A/O process. Sep Purif Technol. 2012;84:9-15.

[9] Flint S, Markle T, Thompson S, Wallace E. Bisphenol A exposure, effects, and policy: A wildlife perspective. J Environ Manage. 2012;104:19-34.

[10] Risk Management Action Milestones for Bisphenol A [Internet]. Canada; Government of Canada; 2012 [cited 2017 Dec 11]. Available from: https://www.canada.ca/en/health-canada/services/chemical-substances/challenge/batch2/bisphenol-a/risk-management-action milestones.html

[11] Durhan EJ, Lambright CS, Makynen EA, Lazorchak J, Hartig PC, Wilson VS, Gray LE, Ankley GT. Identification of metabolites of trenbolone acetate in androgenic runoff from a beef feedlot. Environ Health Perspect. 2006;114;65-68.

[12] Fernandez MP, Ikonomou MG, Buchanan I. An assessment of estrogenic organic contaminants in Canadian wastewaters. Sci Total Environ. 2007;373(1):250-269.

[13] Snyder SA, Westerhoff P, Yoon Y, Sedlak DL. Pharmaceuticals, personal care products, and endocrine disruptors in water: Implications for the water industry. Environ Eng Sci. 2003;20(5):449-469.

[14] Ternes TA, Stumpf M, Mueller J, Haberer K, Wilken R-, Servos M. Behavior and occurrence of estrogens in municipal sewage treatment plants - I. Investigations in Germany, Canada and Brazil. Sci Total Environ. 1999;225(1-2):81-90.

[15] Vethaak AD, Lahr J, Schrap SM, Belfroid AC, Rijs GBJ, Gerritsen A, De Boer J, Bulder AS, Grinwis GCM, Kuiper RV, et al. An integrated assessment of estrogenic contamination and biological effects in the aquatic environment of The Netherlands. Chemosphere. 2005;59(4):511-524.

[16] Körner W, Bolz U, Süßmuth W, Hiller G, Schuller W, Hanf V, Hagenmaier H. Input/output balance of estrogenic active compounds in a major municipal sewage plant in Germany. Chemosphere. 2000;40(9-11):1131-1142. 
[17] Rudder Jd, Wiele TVd, Dhooge W, Comhaire F, Verstraete W. Advanced water treatment with manganese oxide for the removal of 17 $\alpha$-ethynylestradiol (EE2). Water Res. 2004;38(1):184-192.

[18] Yamamoto T, Yasuhara A, Shiraishi H, Nakasugi O. Bisphenol A in hazardous waste landfill leachates. Chemosphere. 2001;42(4):415-418.

[19] Kolpin DW, Furlong ET, Meyer MT, Thurman EM, Zaugg SD, Barber LB, Buxton HT. Pharmaceuticals, hormones, and other organic wastewater contaminants in U.S. streams, 1999-2000: A national reconnaissance. Environ Sci Technol 2002;36(6):12021211.

[20] Stackelberg PE, Furlong ET, Meyer MT, Zaugg SD, Henderson AK, Reissman DB. Persistence of pharmaceutical compounds and other organic wastewater contaminants in a conventional drinking-water-treatment plant. Sci Total Environ. 2004;329(1):99-113.

[21] Wetherill YB, Akingbemi BT, Kanno J, McLachlan JA, Nadal A, Sonnenschein C, Watson CS, Zoeller RT, Belcher SM. In vitro molecular mechanisms of bisphenol A action. Reprod. Toxicol. 2007;24(2):178-198.

[22] Mohapatra DP, Brar SK, Tyagi RD, Surampalli RY. Physico-chemical pretreatment and biotransformation of wastewater and wastewater sludge - Fate of bisphenol A. Chemosphere 2010;78(8):923-941.

[23] Asada T, Oikawa K, Kawata K, Ishihara S, Myobe T, Yamada A. Study of removal effect of bisphenol A and \& ß-Estradiol by porous carbon. J Health Sci. 2004;50(6):588-593.

[24] Nakanishi A, Tamai M, Kawasaki N, Nakamura T, Tanada S. Adsorption characteristics of bisphenol A onto carbonaceous materials produced from wood chips as organic waste. J Colloid Interface Sci. 2002;252(2):393-396.

[25] Tsai W-T, Lai C-W, Su T-Y. Adsorption of bisphenol-A from aqueous solution onto minerals and carbon adsorbents. J Haz Mat. 2006;134(1-3):169-175.

[26] Sudhakar P, Mall ID, Srivastava VC. Adsorptive removal of bisphenol-A by rice husk ash and granular activated carbon-A comparative study. Desalin Water Treat. 2016;57(26):12375-12384.

[27] Sui Q, Huang J, Liu Y, Chang X, Ji G, Deng S, Xie T, Yu G. Rapid removal of bisphenol A on highly ordered mesoporous carbon. J Environ Sci. 2011;23(2):177-182.

[28] Thirunavukkarasu OS, Viraraghavan T, Subramanian KS. Arsenic removal from drinking water using granular ferric hydroxide. Water SA. 2003;29:161-170.

[29] Kilpimaa S, Kuokkanen T, Lassi U. Characterization and utilization potential of wood ash from combustion process and carbon residue from gasification process. Biores 2013;8(1):1011-1027. 
[30] Langmuir I. The adsorption of gases on plane surfaces of glass, mica and platinum. J Am Chem Soc. 1918;40:1361-1403.

[31] Freundlich HMF, Over the adsorption in solution. J Phys Chem. 1906;57:385-471.

[32] Dubinin MM, Radushkevich LV. The equation of the characteristic curve of the activated charcoal. Proc Acad Sci USSR Phys Chem. 1947;55:331-337.

[33] Temkin MJ, Pyzhev V. Recent modifications to Langmuir isotherms. Acta Physicochim URSS. 1940;12:217-222.

[34] Redlich O, Peterson DL. A useful adsorption isotherm. J Phys Chem. 1959;63:1024-1024.

[35] Toth J. State equations of the solid gas interface layer. Acta Chem Acad Hung. 1971;69:311-328.

[36] Sips R. On the structure of a catalyst surface. J Chem Phys. 1948;16:490-495.

[37] Karri RR, Sahu JN, Jayakumar NS. Optimal isotherm parameters for phenol adsorption from aqueous solutions onto coconut shell based activated carbon: Error analysis of linear and non-linear methods. J Taiwan Inst Chem Eng. 2017;80:472-487.

[38] Miraboutalebi SM, Nikouzad SK, Peydayesh M, Allahgholi N, Vafajoo L, McKay G. Methylene blue adsorption via maize silk powder: Kinetic, equilibrium, thermodynamic studies and residual error analysis. Proc Saf Env Protec. 2017;106:191202.

[39] Lagergren S. About the theory of so-called adsorption of soluble substances. K Sven Vetenskapsakad Handl. 1898;24:1-39.

[40] Ho YS, McKay G. Pseudo-second-order model for sorption processes. Process Biochem. 1999;34(5):451-465.

[41] Zeldowitsch J. Über den mechanismus der katalytischen oxydation von CO an $\mathrm{MnO}_{2}$ [About the mechanism of catalytic oxidation of $\mathrm{CO}$ over $\mathrm{MnO}_{2}$ ]. Acta Physicochim URSS. 1934;1:364-449.

[42] Weber WJ, Jr., Morris JC. Kinetics of adsorption of carbon from solution. J Sanit Eng Div/Am Soc Civ Eng. 1963;89:31-60.

[43] Rodríguez-Reinoso F. The role of carbon materials in heterogeneous catalysis. Carbon. 1998;36:159-175.

[44] Fu K, Yue Q, Gao B, Sun Y, Wang Y, Li Q, Zhao P, Chen S. Physicochemical and adsorptive properties of activated carbons from Arundo donax Linn utilizing different iron salts as activating agents. J Taiwan Inst Chem Eng. 2014;45(6):3007-3015. 
[45] Koduru JR, Lingamdinne LP, Singh J, Choo K. Effective removal of bisphenol A (BPA) from water using a goethite/activated carbon composite. Process Saf Environ Prot. 2016;103:87-96.

[46] Park H, Koduru JR, Choo K, Lee B. Activated carbons impregnated with iron oxide nanoparticles for enhanced removal of bisphenol A and natural organic matter. $\mathrm{J}$ Haz Mat. 2015;286:315-324.

[47] Gong J, Wang B, Zeng G, Yang C, Niu C, Niu Q, Zhou W, Liang Y. Removal of cationic dyes from aqueous solution using magnetic multi-wall carbon nanotube nanocomposite as adsorbent. J Haz Mat. 2009;164(2):1517-1522.

[48] Bautista-Toledo I, Ferro-García MA, Rivera-Utrilla J, Moreno-Castilla C, Vegas Fernández FJ. Bisphenol A removal from water by activated carbon. Effects of carbon characteristics and solution chemistry. Environ Sci Technol. 2005;39(16):6246-6250.

[49] Tang L, Zhihong X, Guangming Z, Dong H, Fan C, Zhou Y, Wang J, Deng Y, Wang J, Wei X. Removal of bisphenol A by iron nanoparticle-doped magnetic ordered mesoporous carbon. RSC Adv. 2016;6:25724-25732.

[50] Poerschmann J, Trommler U, Górecki T. Aromatic intermediate formation during oxidative degradation of Bisphenol A by homogeneous sub-stoichiometric Fenton reaction. Chemosphere. 2010;79(10):975-986.

[51] Potakis N, Frontistis Z, Antonopoulou M, Konstantinou I, Mantzavinos D. Oxidation of bisphenol A in water by heat-activated persulfate. J Environ Manag. 2017;195:125-132.

[52] Tsai W-T, Lee M-K, Su T-Y, Chang Y-M. Photodegradation of bisphenol-A in a batch $\mathrm{TiO}_{2}$ suspension reactor. J Haz Mat. 2009;168(1):269-275.

[53] Luo S, Yang S, Sun C, Wang X. Feasibility of a two-stage reduction/subsequent oxidation for treating Tetrabromobisphenol $\mathrm{A}$ in aqueous solutions. Water Res. 2011;45(4):1519-1528.

[54] Hua Z, Ma W, Bai X, Feng R, Yu L, Zhang X, Dai Z. Heterogeneous Fenton degradation of bisphenol A catalyzed by efficient adsorptive $\mathrm{Fe}_{3} \mathrm{O}_{4} / \mathrm{GO}$ nanocomposites. Environ Sci Pollut Res. 2014;21(12):7737-7745.

[55] Sabhi S, Kiwi J. Degradation of 2,4-dichlorophenol by immobilized iron catalysts. Water Res. 2001;35(8):1994-2002.

[56] Bahnemann W, Muneer M, Haque MM. Titanium dioxide-mediated photocatalysed degradation of few selected organic pollutants in aqueous suspensions. Catal Today. 2007;124(3-4):133-148.

[57] Daskalaki VM, Frontistis Z, Mantzavinos D, Katsaounis A. Solar light-induced degradation of bisphenol-A with $\mathrm{TiO}_{2}$ immobilized on Ti. Catal Today. 2011;161(1):110-114. 
Table 1. Specific surface areas, pore sizes and volumes of sorbents.

\begin{tabular}{|c|c|c|c|c|c|c|c|c|c|c|}
\hline & BET & & & BJH & & & & [\%] & & \\
\hline Sample & $\begin{array}{l}\mathrm{BET} \\
\mathrm{m}^{2} / \mathrm{g}\end{array}$ & $\begin{array}{l}\text { Pore } \\
\text { volume } \\
\mathrm{cm}^{3} / \mathrm{g}\end{array}$ & $\begin{array}{l}\text { Pore } \\
\text { size } \\
\mathrm{nm}\end{array}$ & $\begin{array}{l}\text { Micro } \\
\mathrm{d}<2 \mathrm{~nm} \\
\mathrm{~cm}^{3} / \mathrm{g}\end{array}$ & $\begin{array}{l}\text { Meso } \\
2< \\
\mathrm{d}<50 \\
\mathrm{~nm} \\
\mathrm{~cm}^{3} / \mathrm{g}\end{array}$ & $\begin{array}{l}\text { Macro } \\
\mathrm{d}>50 \\
\mathrm{~nm} \\
\mathrm{~cm}^{3} / \mathrm{g}\end{array}$ & $\begin{array}{l}\text { Total } \\
\text { volume } \\
\mathrm{cm}^{3} / \mathrm{g}\end{array}$ & $\begin{array}{l}\text { Micro } \\
\mathrm{d}<2 \text { nm }\end{array}$ & $\begin{array}{l}\text { Meso } \\
2< \\
\mathrm{d}<50 \\
\mathrm{~nm}\end{array}$ & $\begin{array}{l}\text { Macro } \\
\text { d }>50 \\
n m\end{array}$ \\
\hline $\begin{array}{l}\text { Fe-CR } \\
\text { fresh }\end{array}$ & 103.0 & 0.146 & 5.70 & 0.010 & 0.109 & 0.018 & 0.137 & 7.30 & 79.6 & 13.1 \\
\hline $\begin{array}{l}\text { Fe-CR } \\
\text { used }\end{array}$ & 96.6 & 0.139 & 5.80 & 0.009 & 0.105 & 0.016 & 0.130 & 7.08 & 80.8 & \\
\hline $\begin{array}{l}\text { H-CR } \\
\text { fresh }\end{array}$ & 74.0 & 0.109 & 5.89 & 0.011 & 0.009 & - & 0.019 & 55.5 & 44.5 & \\
\hline $\begin{array}{l}\text { H-CR } \\
\text { used }\end{array}$ & 57.8 & 0.098 & 6.79 & 0.008 & 0.007 & - & 0.015 & 55.5 & & \\
\hline $\begin{array}{l}\text { Ca-CR } \\
\text { fresh }\end{array}$ & 76.9 & 0.113 & 5.88 & 0.011 & 0.008 & - & 0.019 & & & \\
\hline $\begin{array}{l}\text { Ca-CR } \\
\text { used }\end{array}$ & 62.0 & 0.110 & 7.10 & 0.009 & 0.007 & - & 0.016 & & & - \\
\hline
\end{tabular}

Table 2. Isotherm parameters and errors for the sorption BPA removal on Fe-CR, H-CR and Ca-CR.

\begin{tabular}{|c|c|c|c|}
\hline $\begin{array}{l}\text { Experimental/ } \\
\text { Model }\end{array}$ & $\begin{array}{l}\text { Constant } \\
\text { [unit] }\end{array}$ & $\mathrm{H}-\mathrm{CR}$ & Ca-CR \\
\hline Experimental & $\mathrm{q}_{\mathrm{m}}[\mathrm{mg} / \mathrm{g}]$ & 23.84 & 16.84 \\
\hline Sips & $\begin{array}{ll}\mathrm{q}_{\mathrm{m}}[\mathrm{mg} / \mathrm{g}] & 62.15 \\
\mathrm{~b}_{\mathrm{S}}[\mathrm{L} / \mathrm{mg}] & 0.093 \\
\mathrm{n}_{\mathrm{S}} & 1.658 \\
\mathrm{R}^{2} & 0.963 \\
\mathrm{RMSE} & 3.205\end{array}$ & $\begin{array}{l}27.95 \\
0.079 \\
1.740 \\
0.922 \\
2.863\end{array}$ & $\begin{array}{l}17.73 \\
0.072 \\
6.218 \\
0.986 \\
0.904\end{array}$ \\
\hline
\end{tabular}

Model solution. Initial pH; 4 for Fe-CR and Ca-CR, pH 5 for H-CR, $\mathrm{C}_{0}(\mathrm{BPA}): 60 \mathrm{mg} / \mathrm{L}$, $\mathrm{m}$ (sorbent): $5 \mathrm{~g} / \mathrm{L}$, contact time: $24 \mathrm{~h}$ and temperature $22-23^{\circ} \mathrm{C}$. 
Table 3. Comparison of sorption capacity $q_{m}(\mathrm{mg} / \mathrm{g})$ of various sorbents for the removal of bisphenol from aqueous phase.

\begin{tabular}{|l|l|l|l|l|l|}
\hline Sorbent & $\begin{array}{l}\text { Capacity } \\
\mathrm{q}(\mathrm{mg} / \mathrm{g})\end{array}$ & $\mathrm{c}[\mathrm{mg} / \mathrm{L}]$ & $\begin{array}{l}\text { Sorbent } \\
\text { dosage }[\mathrm{g} / \mathrm{L}]\end{array}$ & Time & Reference \\
\hline $\begin{array}{l}\text { Carbon from Moso bamboo } \\
\left(400{ }^{\circ} \mathrm{C}\right)\end{array}$ & $2.1^{\mathrm{a}}$ & $<1000$ & 0.1 & $24 \mathrm{~h}$ & {$[23]$} \\
\hline $\begin{array}{l}\text { Carbon from wood } \\
\text { processing by-product } \\
\left(600^{\circ} \mathrm{C}\right)\end{array}$ & $4.2-18.2^{\mathrm{a}}$ & n.a & n.a & $48 \mathrm{~h}$ & {$[24]$} \\
\hline $\begin{array}{l}\text { Carbon from Moso bamboo } \\
\left(700^{\circ} \mathrm{C}\right)\end{array}$ & $11.4^{\mathrm{a}}$ & $<1000$ & 0.1 & $24 \mathrm{~h}$ & {$[23]$} \\
\hline $\begin{array}{l}\text { Carbon from wood } \\
\text { processing by-product } \\
\left(800^{\circ} \mathrm{C}\right)\end{array}$ & $24.1-31.4^{\mathrm{a}}$ & n.a & n.a & $48 \mathrm{~h}$ & {$[24]$} \\
\hline Iron-modified carbon & $41.5^{\mathrm{b}}$ & 60 & 5.0 & $24 \mathrm{~h}$ & This study \\
\hline $\begin{array}{l}\text { Carbon from Moso bamboo } \\
\left(1000{ }^{\circ} \mathrm{C}\right)\end{array}$ & $41.8^{\mathrm{a}}$ & $<1000$ & 0.1 & $24 \mathrm{~h}$ & {$[23]$} \\
\hline $\begin{array}{l}\text { Activated carbon from } \\
\text { almond shells }\end{array}$ & $188.9^{\mathrm{a}}$ & $50-350$ & 1 & 7 days & {$[48]$} \\
\hline $\begin{array}{l}\text { Activated carbon from } \\
\text { coconut shells }\end{array}$ & $328.3^{\mathrm{a}}$ & $60-100$ & $0.05-0.25$ & $2 \mathrm{~h}$ & {$[25]$} \\
\hline
\end{tabular}

${ }^{\mathrm{a}}$ Langmuir maximum sorption capacity, $\mathrm{q}_{\mathrm{m} \text {,calc, }}{ }^{\mathrm{b}}$ Experimental maximum sorption capacity n.a not available

Table 4. Pseudo-first-order, pseudo-second-order and Elovich model parameters for Femodified carbon residue (Fe-CR), acid washed $\mathrm{CaCl}_{2}$ treated $\mathrm{CR}$ (Ca-CR) and acidwashed carbon residue (H-CR) in BPA removal.

\begin{tabular}{|c|c|c|c|c|c|}
\hline \multicolumn{6}{|c|}{ Pseudo-first-order model } \\
\hline Sorbent & $\begin{array}{l}\mathrm{q}_{\mathrm{e}, \exp } \\
(\mathrm{mg} / \mathrm{g})\end{array}$ & (mg/g) & $(1 / \mathrm{min})$ & $\mathrm{R}^{2}$ & RMSE \\
\hline Fe-CR & 11.59 & 1.16 & 2.45 & 0.990 & 0.328 \\
\hline $\mathrm{H}-\mathrm{CR}$ & 10.87 & 10.61 & 2.73 & 0.993 & 0.228 \\
\hline Ca-CR & 10.45 & & 2.44 & 0.996 & 0.164 \\
\hline \multicolumn{6}{|c|}{ Pseudo-second-order } \\
\hline Sorbent & & & $\mathrm{k}_{2}$ (g/mg min) & $\mathrm{R}^{2}$ & RMSE \\
\hline Fe-CR & 11.59 & 11.27 & 0.75 & 0.996 & 0.216 \\
\hline $\mathrm{H}-\mathrm{CR}$ & 10.78 & 10.72 & 0.98 & 0.998 & 0.123 \\
\hline Ca-CR & 10.45 & 10.29 & 0.97 & 0.999 & 0.088 \\
\hline \multicolumn{6}{|c|}{ Elovich model } \\
\hline & & ${ }^{b}{ }_{(g / L)}$ & $\begin{array}{l}v_{0} \\
\quad(\mathrm{mg} / \mathrm{g} \min )\end{array}$ & $\mathrm{R}^{2}$ & RMSE \\
\hline -CR & 11.59 & 5.59 & $3.40 \cdot 10^{24}$ & 0.999 & 0.0874 \\
\hline $\mathrm{H}-\mathrm{CR}$ & 10.87 & 7.96 & $1.35 \cdot 10^{34}$ & 0.998 & 0.108 \\
\hline $\mathrm{Ca}-\mathrm{CR}$ & 10.45 & 7.77 & $5.91 \cdot 10^{31}$ & 0.998 & 0.114 \\
\hline
\end{tabular}


Table 5. Thermodynamic parameters for the sorption of BPA on studied sorbents at different temperatures.

\begin{tabular}{lllll}
\hline Sorbent & Temperature $\left({ }^{\circ} \mathrm{C}\right)$ & $\Delta \mathrm{G}(\mathrm{kJ} / \mathrm{mol})$ & $\Delta \mathrm{S}(\mathrm{J} / \mathrm{mol} \mathrm{K})$ & $\Delta \mathrm{H}(\mathrm{kJ} / \mathrm{mol})$ \\
\hline Fe-CR & 10 & -19.3 & & \\
& 22 & -21.2 & 126.2 & 16.3 \\
H-CR & 40 & -23.1 & & \\
& 10 & -14.9 & 145.5 & 25.9 \\
& 22 & -18.0 & & \\
Ca-CR & 40 & -19.3 & & 26.7 \\
& 10 & -15.3 & 147.0 & \\
& 22 & -16.1 & & \\
\hline
\end{tabular}

Table 6. Evolution of sorption and desorption capacity of Fe-CR after each cycle. The sorbent dosage $5 \mathrm{~g} / \mathrm{L}$, BPA concentration $60 \mathrm{mg} / \mathrm{L}, \mathrm{pH}: 4$, time $48 \mathrm{~h} /$ cycle.

\begin{tabular}{lll}
\hline Cycle & $\mathbf{q}(\mathbf{m g} / \mathbf{g})$ & \\
& Sorption & Desorption \\
\hline 1 & 11.6 & 5.6 \\
2 & 11.7 & 5.1 \\
3 & 11.7 & 4.9 \\
\hline
\end{tabular}


Fig. 1. FESEM image of Fe-CR, iron particles are marked with an arrow, magnification $5000 X$

Fig. 2. Total BPA removal percent (left, solid lines) and sorption capacity (right, dashed lines) versus initial $\mathrm{pH}$ on the sorption of BPA from aqueous solution. Sorbent dosage: $5 \mathrm{~g} / \mathrm{L}$, contact time: $24 \mathrm{~h}$, temperature: $22-23^{\circ} \mathrm{C}$, sorbate: synthetic solution $\left(\mathrm{C}_{0}\right.$, BPA: $60 \mathrm{mg} / \mathrm{L})$. Note, the left y-axis does not start from zero.

Fig. 3. Effect of sorbent mass. Total BPA removal percent (left, solid lines) and sorption capacity (right, dashed lines) versus sorbent dosage on the sorption of BPA from aqueous solution. Initial $\mathrm{pH}$ : 4, 5 and 4 for Fe-CR, $\mathrm{H}-\mathrm{CR}$ and $\mathrm{Ca}-\mathrm{CR}$, respectively, contact time: $24 \mathrm{~h}$, temperature: $22-23{ }^{\circ} \mathrm{C}$, sorbate: synthetic solution ( $\mathrm{C}_{0}, \mathrm{BPA}: 60$ $\mathrm{mg} / \mathrm{L})$. Note, the left y-axis does not start from zero.

Fig. 4. The Sips isotherms for the studied sorbents. Initial $\mathrm{pH}: 4,5$ and 4 for Fe-CR, H$\mathrm{CR}$ and Ca-CR, respectively, contact time: $24 \mathrm{~h}$, temperature: $22-23^{\circ} \mathrm{C}$, sorbate: synthetic solution $\left(\mathrm{C}_{0}\right.$, BPA: $\left.60 \mathrm{mg} / \mathrm{L}\right)$.

Fig. 5. Kinetic data of sorption of the BPA onto the Fe-CR, H-CR and Ca-CR. Best fitted models for the experimental results are also shown. Highest correlation coefficient for the Ca-CR was reached using pseudo-second-order model (dashed line). For the FeCR the Elovich model (straight line) gave highest $\mathrm{R}^{2}$-value. For the H-CR both pseudosecond-order (dashed line) and Elovich model are shown since they got equal $\mathrm{R}^{2}$-values. The experiments were performed on room temperature, the sorbent dosage was $5 \mathrm{~g} / \mathrm{L}$, BPA concentration was $60 \mathrm{mg} / \mathrm{L}$. Initial $\mathrm{pH}$ was 4,5 and 4 for Ca-CR, H-CR and FeCR, respectively.

Fig. 6. Weber \& Morris intraparticle diffusion model plots of BPA on the studied sorbents. The experiments were performed on room temperature, the sorbent dosage was $5 \mathrm{~g} / \mathrm{L}$, BPA concentration was $60 \mathrm{ppm}$. Initial pH was 4, 5 and 4 for Fe-CR, H-CR and Ca-CR, respectively.

Fig. 7. BPA adsorption-desorption cycles. The Fe-CR sorbent dosage 5g/L, BPA concentration $60 \mathrm{mg} / \mathrm{L}, \mathrm{pH}$ : 4, time 48 h/cycle. 

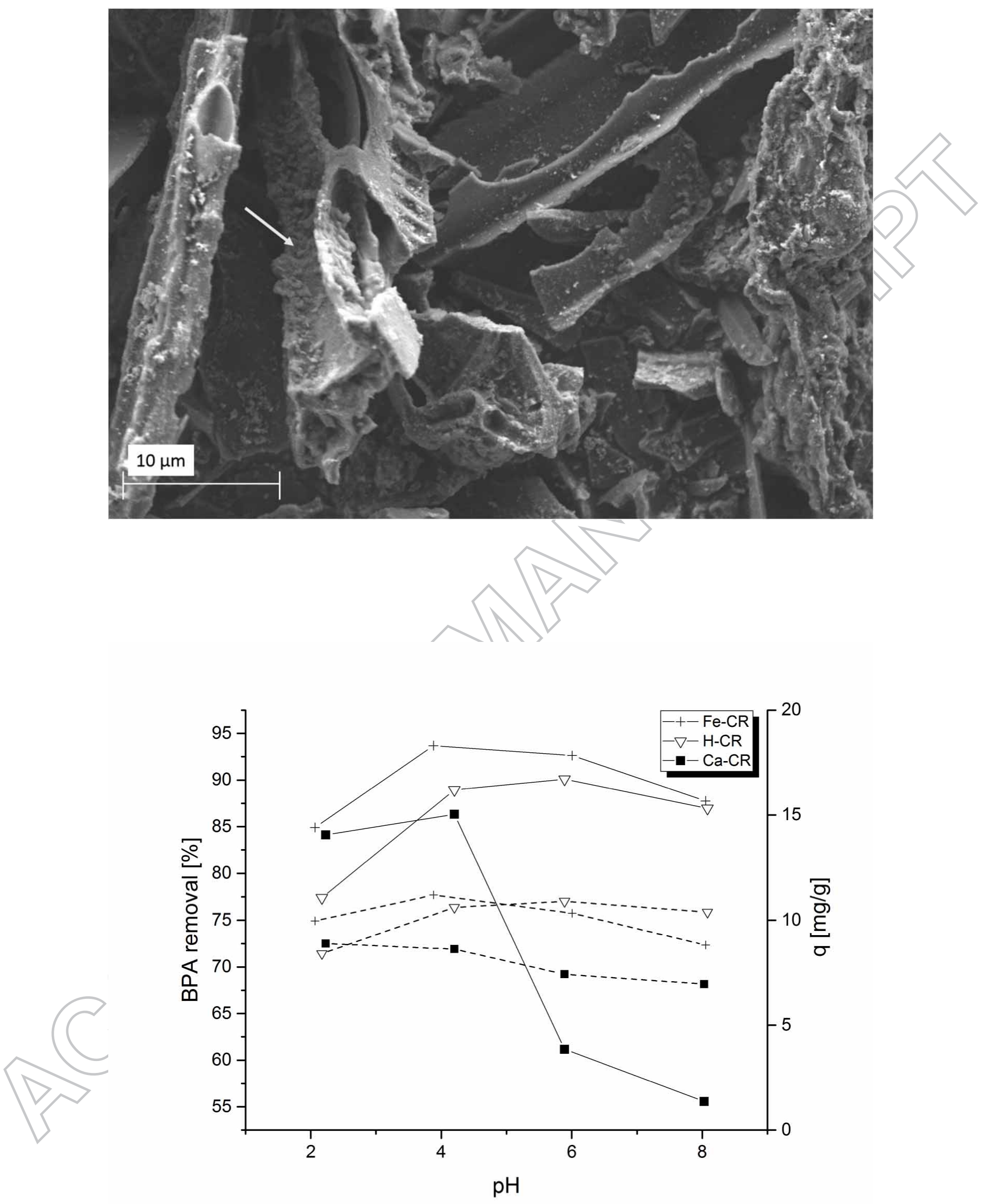


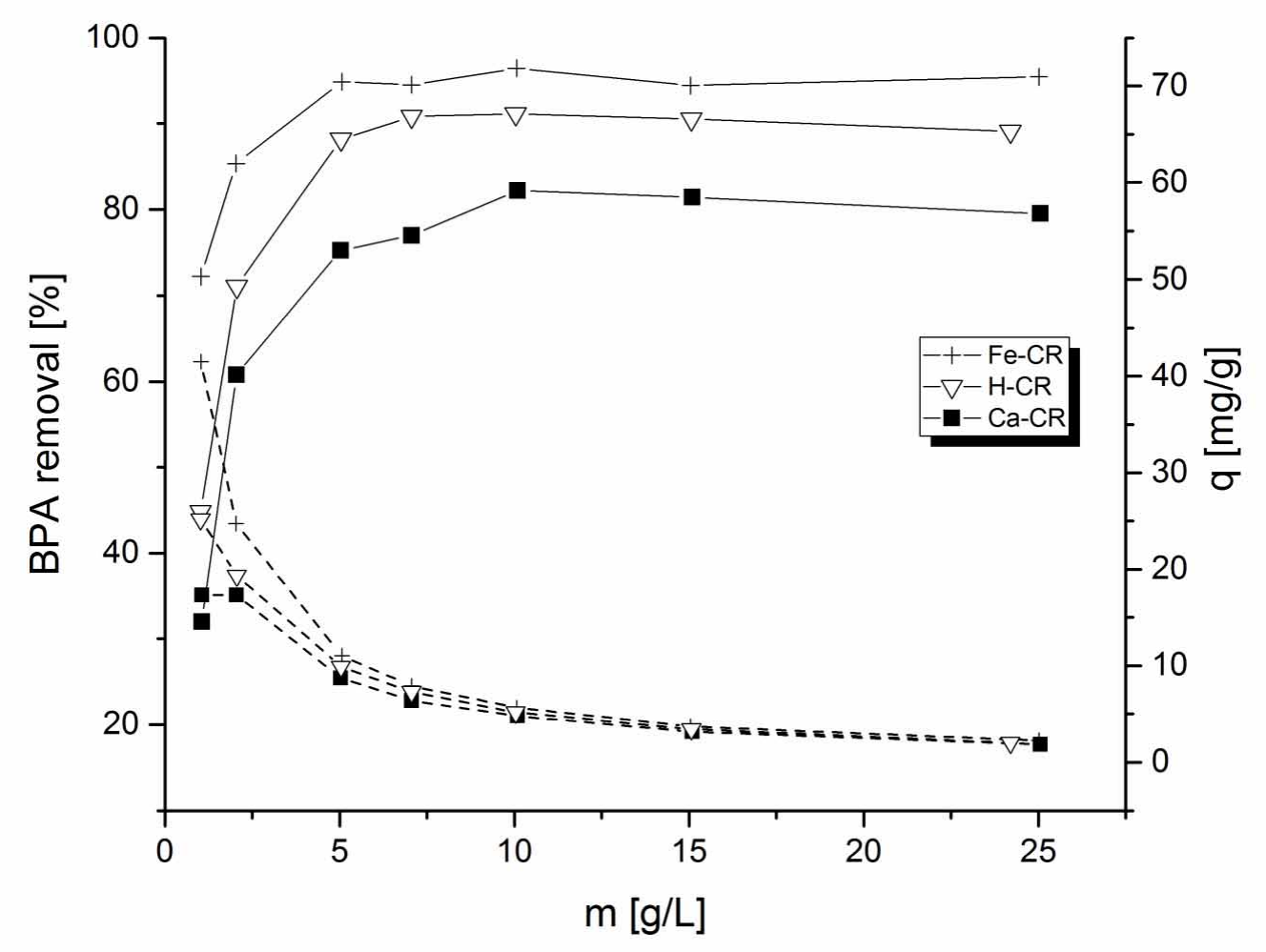




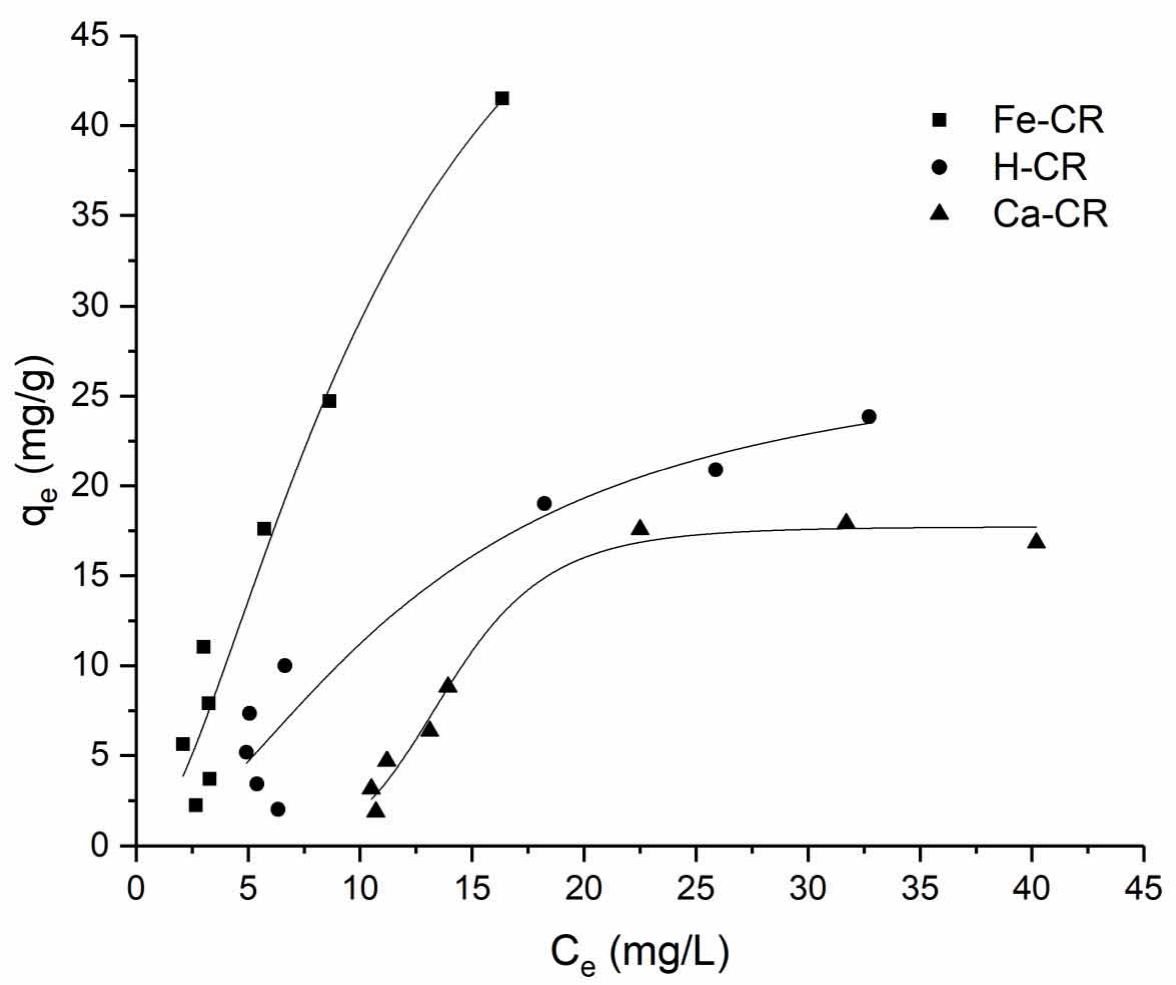



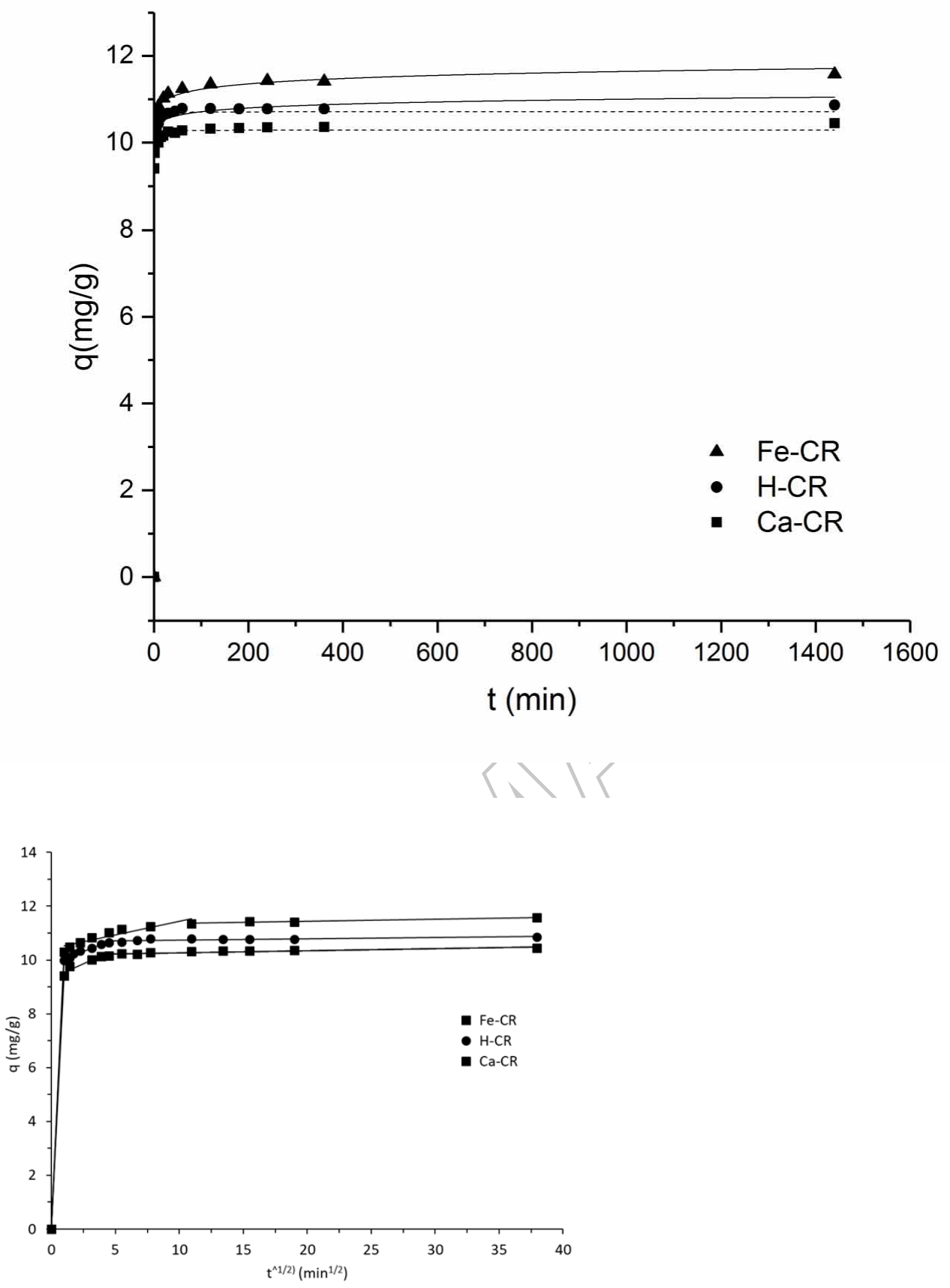

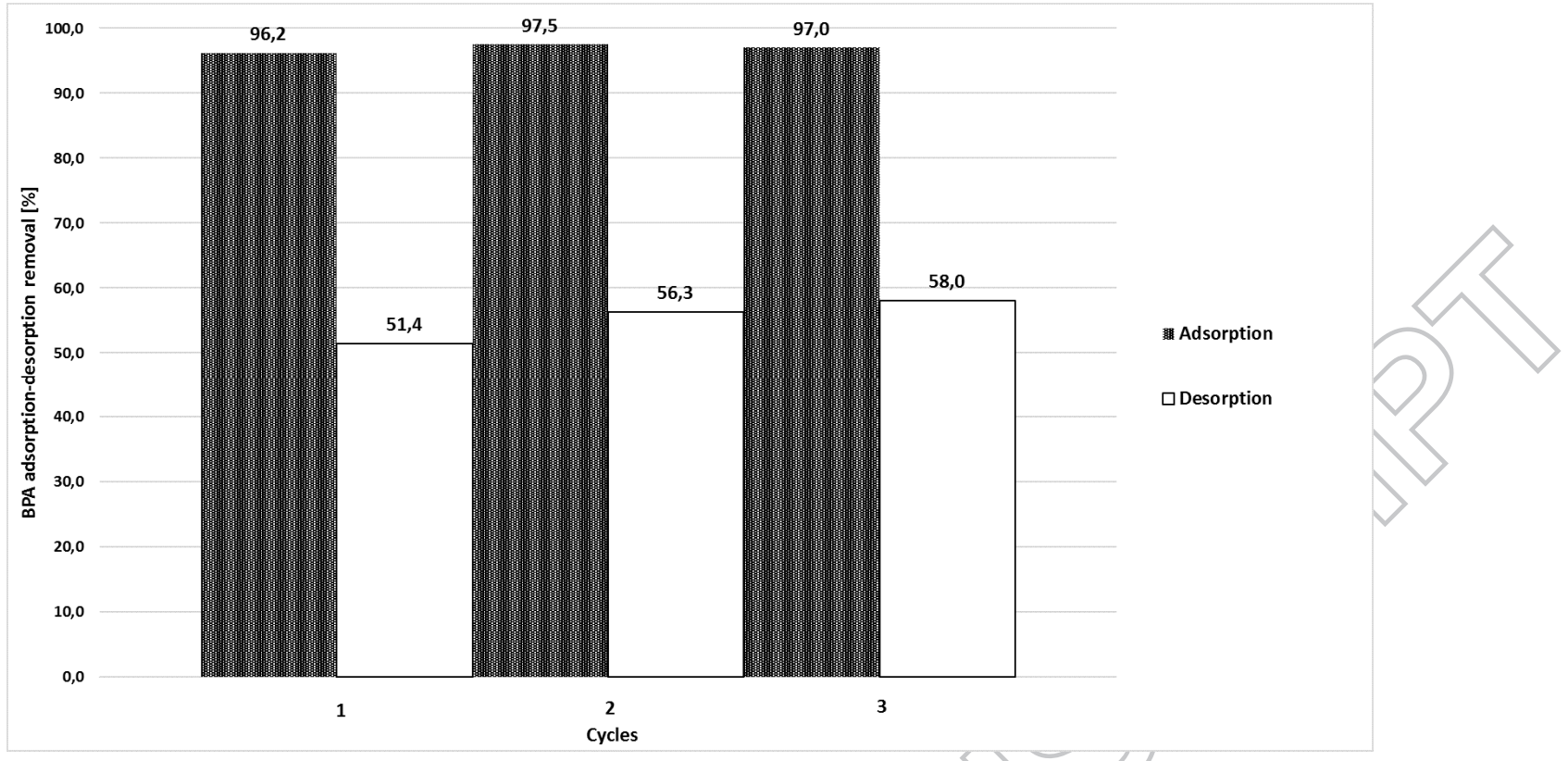